\title{
Copyright resources on the Web Sites to keep you current
}

$\mathbf{T}^{\mathrm{T}}$ he concept of copyright is an integral part of U.S. culture and law. From its inclusion in the U.S. Constitution to the recent passages of several key acts, such as the Copyright Term Extension Act and the Digital Millennium Copyright Act, copyright has continued to grow and evolve as advances in technology change the way we store and transmit information. As ink and paper are replaced by bits and bytes and classrooms move into cyberspace, the issue of copyright has never been more relevant to individuals who work in libraries, archives, classrooms, etc. While the legislative and judiciary bodies scramble to keep up with the rapid pace of changing technologies, information professionals will need to actively work to stay current with copyright laws, guidelines, and best practices as they relate to the services they provide.

The resources presented here offer librarians, educators, and other information professionals a wide range of information on copyright from the introductory, to the practical, to the philosophical. There is no shortage of resources on the Web that tackle this thorny issue; a comprehensive listing of Internet resources, and the related issues of intellectual property and digital rights management, could easily consume volumes. The challenge is nding resources that are well designed, current, and authoritative without bogging the reader in legalese or jargon. The following Web sites are just a slice of some of the better resources one will nd when researching the topic.

\section{Accessing and interpreting guidelines and law}

CONTU Guidelines on Photocopying under Interlibrary Loan Arrangements.
Interlibrary loan services rely in part on CONTU s (National Commission on New Technological Uses of Copyright Works) guidelines for reproducing copyrighted works. The guidelines specify criteria such as the amount and frequency of reproductions and the proper way to document transactions. Access: http://www.cni.org/docs/infopols /CONTU.html.

U.S. Code Collection. Title 17 covers U.S. copyright law. Section 108 should interest all information seekers as it grants rights that are fundamental to the operation of libraries. The code is searchable by keyword (Boolean operators and wildcards are supported) as well as title and section. Access: http://www4.law.cornell.edu/uscode/.

Digital Millennium Copyright Act. The text of the bills from the Library of Congress. Access: http://thomas.loc.gov/cgi-bin /query/z?c105:H.R.2281:. DMCA is a hotly debated topic; for a long, but fairly objective background and summary of the law, see the U.S. Copyright Of ce s text of the Executive Summary. Access: http://www.copyright.gov /reports/studies/dmca/dmca_executive.html.

Library Digitization Projects \& Copyright. Analysis and interpretation of copyright law from attorney (and former librarian) Mary Minow. Minow provides information on major issues such as public domain, permissions, and fair use. Her explanations are clear and her analysis draws on everyday scenarios and examples. Note the extensive footnoting as she provides links to many of

David Hodgins is head of access services at Methodist University, e-mail: dhodgins@methodist.edu

(c) 2007 David Hodgins 
the resources she cites. Access: http://www. llrx.com/features/digitization.htm.

The TEACH Toolkit. An in-depth look at the TEACH Act by North Carolina State University. The TEACH Act is composed of complex sets of requirements and circumstances that are made considerably more palatable by the TEACH Toolkit. The toolkit provides basic and expanded checklists and a best practices for incorporating TEACH in the online classroom. Access: http://www.lib. ncsu.edu/scc/legislative/teachkit/.

\section{2] The TEACH Toolkit}

United States Copyright Office. The law and policy section of the site conveniently provides PDF and TXT versions of Title 17 and recent legislation. In addition, well-designed fact sheets, brochures, and circulars are available for printing. There is also a link to recent/pending legislation and updates from the Librarian of Congress. The U.S. Copyright Of ce is an authority on the subject, and they are not shy about sharing their knowledge and resources. Individuals seeking copyrights will nd comprehensive information on the registration process and links to the necessary forms. A searchable database of existing copyright registrations and documents (since 1978) is available, as well as information on the search process. Access: http://www.copyright.gov/.

\section{Academics}

Catholic University of America, the Office of General Council. Extensive information and explanation of the law and current legislation. The Q\&A section provides real world examples of applying laws and guidelines. Access: http://counsel.cua.edu /copyright/index.cfm.

Copyright Management Center. A resource from Indiana University that provides information that will be useful for beginners and veterans alike. The former should see the Copyright Quick guide, which provides a brief introduction and background to

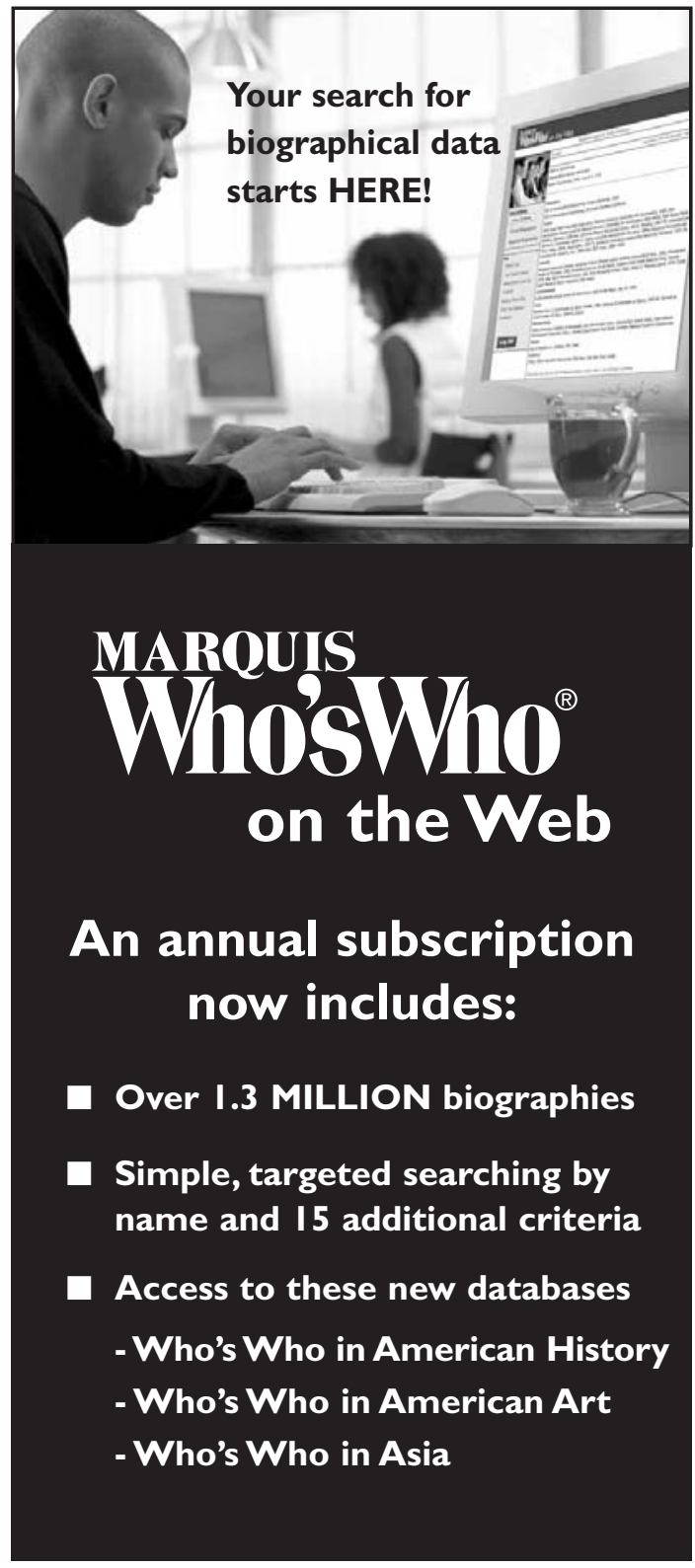

“...an absolutely essential research tool. Recommended with gusto for all libraries." Library Journal, November, 2006

To request a free trial, call Michael Noerr at I-800-473-7020, ext. 1044, or e-mail sales@marquiswhoswho.com

Be sure to reference "CRLI06" to receive your free trial. 
copyright. The Fair Use and Permissions Information will be of interest to the latter. These sections contain a wealth of practical information and links to further resources about services, such as reserves, interlibrary loan, distance education, etc. Access: http:// www.copyright.iupui.edu/.

Copyright Term and the Public Domain in the United States. A useful resource for determining a work s copyright status. The page is part of the Cornell Copyright Information Center, which contains a respectable number of links to internal and external copyright resources. Access: http:// www.copyright.cornell.edu/training/Hirtle _Public_Domain.htm.

Electronic Reserves Resources. A collection of resources devoted to electronic reserves. Ignore the potentially head-spinning background and one nds a healthy collection of links to information about electronic reserves and copyright, including current policies at several colleges and universities. Access: http://www.mville.edu/Administration /staff/Jeff_Rosedale/.

Stanford University Libraries: Copyright and Fair Use. Stanford University Libraries provides information and resources on, among other areas, the murky topic of fair use. Note the section titled Summaries of Fair Use Cases, which draws upon case history to provide real world examples of application of the law. Access: http://fairuse. stanford.edu/.

The University of Texas System: Copyright Crash Course. A highly comprehensive resource. Don t let the clumsy site design fool you; buried in the various links is a treasure trove of information, useful to indi-

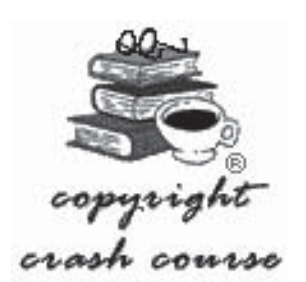
viduals at all levels. There is a tremendous amount of practical information on library services, such as reserves, interlibrary loan, and distance education. In addition the site offers online tutorials (organized by academic status, such as administrator, faculty, student, etc.) and a video tutorial in Flash format. Access: http://www.utsystem.edu/ogc /IntellectualProperty/cprtindx.htm.

\section{Resources and policies of professional organizations}

ALA. ALA provides information on topics such as fair use, electronic reserves, digital rights management, licensing, etc. Be sure to check out the Federal Legislation section or you will miss other important topics like the DMCA, TEACH Act, and orphaned works. Access: http://www.ala.org/ala/washoff /WOissues/copyrightb/copyright.htm.

Association of Research Libraries (ARL). ARL s Public Policy page on Copyright and Intellectual Property is woefully out of date; most of the recent links date to mid2006 and the most recent topic in Recent News is from mid-2005. There is however a fairly comprehensive coverage of DMCA and TEACH Act, as well as links to articles in ARL publications that address copyright. Access: http://www.arl.org/info/frn/copy /copytoc.html.

Copyright Advisory Network. An ALA site designed to give librarians a place to learn about and discuss issues related to copyright. What it lacks in content it makes up for in a healthy serving of links to other resources. They also offer a discussion forum where users can seek assistance from Copyright Advisory Network participants and forum members. Access: http://www. librarycopyright.net/.

Copyright for Music Librarians. A resource by the Music Library Association that contains an in-depth and well-organized FAQ, compete with real world scenarios and examples. The information is not limited to music or multimedia; the guidelines section covers topics such as fair use and reserves. Access: http://www.lib.jmu.edu/org/mla/.

\section{Permissions and licensing}

Association of American Publishers. Solid information on the permissions process; they give suggestions for implementing effective and ef cient permissions processing as well as tips for contacting rights holders. 
The association maintains a list of members names, addresses, and (infrequently) direct contact information for rights and permissions. Access: http://www.publishers.org /copyright/index.cfm.

Copyright Clearance Center (CCC). CCC is your one-stop shopping site for managing copyright permissions. The site is well organized and the search interface (which supports some BOOLEAN operators and wildcards) is effective and easy to use. Permissions are organized by type of use (interlibrary loan, e-reserve, course packet, etc.) and are searchable by publication title, publisher name, or standard number (ISSN or ISBN). Access: http://www.copyright.com/.

\section{(EC) Copyright Clearance Center}

Creative Commons (CC). CC is a nonpro t organization that provides authors with (free) tools to manage their intellectual property. A CC license in essence allows others to reproduce a licensed work when they give credit to the license holder. The Web site has a tool that generates licenses (in HTML format) based on chosen criteria. Access: http://creativecommons.org/.

LIBLICENSE. Comprehensive information about licensing digital information. The site makes available for download a program that can be used to create licenses. The information presented is useful not only to persons interested in developing licenses, but to anyone looking for assistance in deciphering the language of licensing agreements, which are often laced with legalese and unfamiliar terms. Access: http://www. library.yale.edu/ llicense/.

\section{Advocacy}

Chilling Effects. A project supported by the Electronic Freedom Frontier and law school clinics across the country. Chilling Effects seeks to promote intellectual freedom at a time when the threat of litigation might otherwise keep people from using new technologies to express themselves. Their extensive FAQ section covers additional subtopics, such as reverse engineering and anti-circumvention, hot topics in large part to DMCA restrictions. Access: http://www. chillingeffects.org/copyright/.

\section{Chilling Effects}

Copyright Kids. A product of the American Copyright Association that seeks to inform children about copyright. The site includes a tutorial that uses a scenario of students creating a school yearbook to address various copyright issues. The site is clumsy and dif cult to navigate in areas, but explains concepts and de nitions in a way that should be easily understood by a younger crowd. Access: http://www.copyrightkids.org/.

Electronic Frontier Foundation (EFF). EFF s mission is defending freedom in the digital world. The site has two sections that should be of particular interest to the reader: Intellectual Property and Fair Use and DRM. EFF offers background

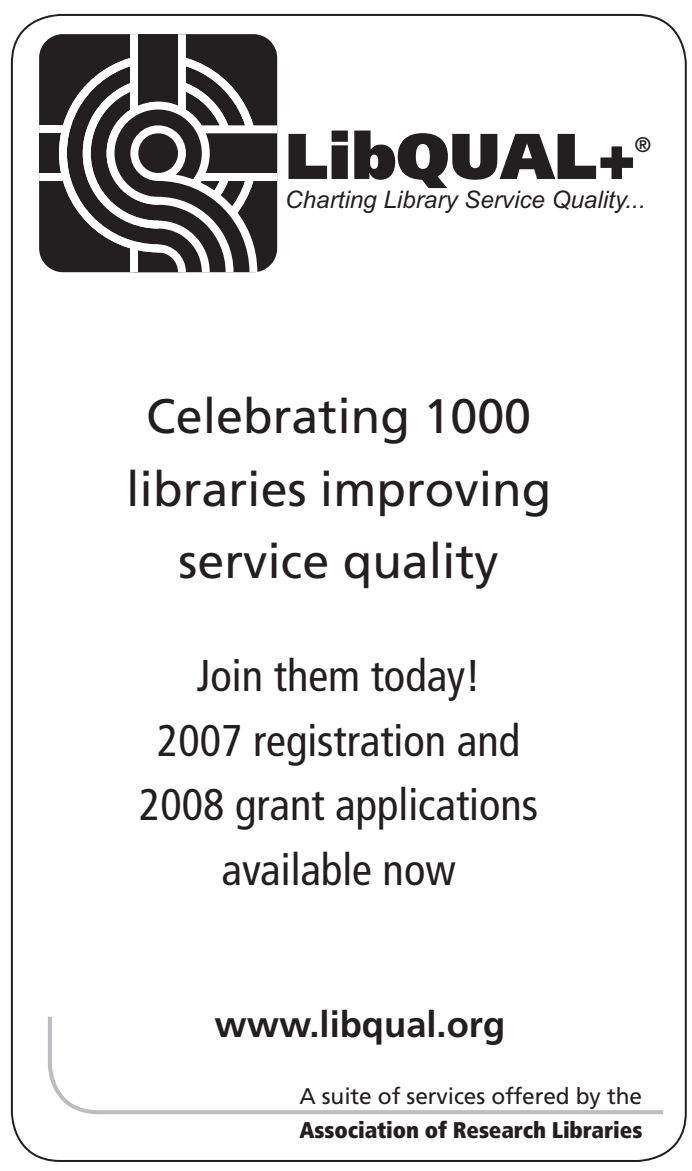


information on major topics, research, legislation, etc., with a strong focus on digital audio and visual, though the underlying concepts and ideas such as digital rights management, fair use, DCMA, etc. should be relevant to all information professionals. Access: http://www.eff.org/.

The Fair Use Network. As part of the Free Expression Policy Project, the Fair Use Network exists to promote freedom of expression and assist individuals who have questions about, among other things, fair use and copyright law. Their blog tracks current copyright events and links to other advocacy sites. In addition they provide basic descriptions of copyright law and a Glossary \& Index of Legal Terms. Access: http://fairusenetwork.org/.

The Free Expression Policy Project (FEPP). FEPP advocates for many issues related to intellectual property rights. It provides news and commentary as well as their own policy reports. Navi- gating the site can be challenging; click the Copyright menu button to see an aggregate of links on the subject. Access: http://fepproject.org/.

World International Policy Organization (WIPO). WIPO is an agency of the United Nations whose aim is developing a balanced and accessible international intellectual (IP) system . . . Their Copyright section provides links to reports, publications, treaties, etc. Access: http://www.wipo. int/copyright/en/.

\section{Discussion lists and bulletin boards}

Coalition for Networked Information. Access: http://www.cni.org/Hforums /cni-copyright/.

Copyright Advisory Network Forum. Access: http://www.librarycopyright.net/ wordpress/punbb/viewforum.php?id=1.

Online Forum On Intellectual Property in the Informational Age. Access: http://www.wipo.int/ipisforum/en/. 2

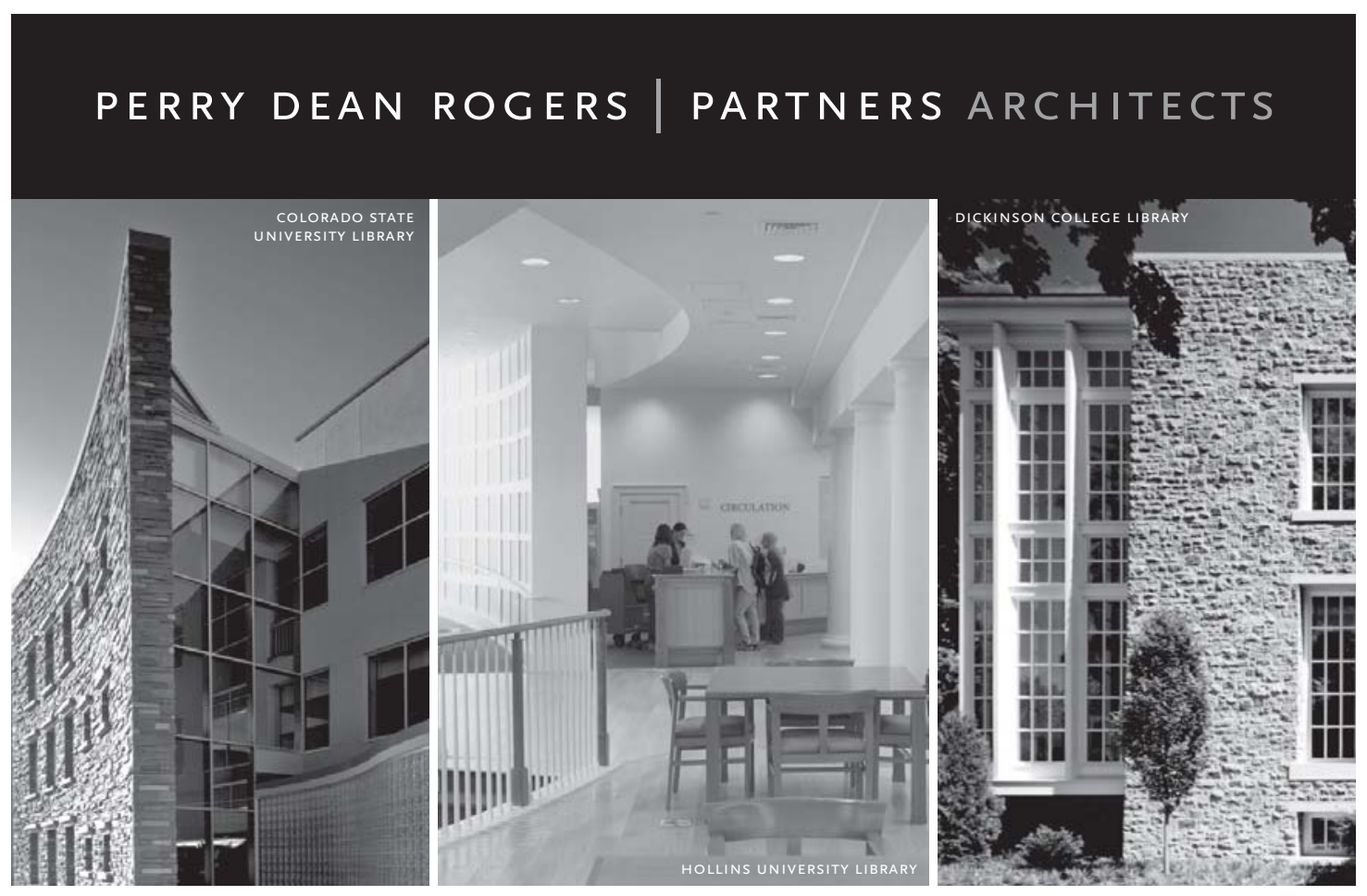

Designers for Libraries \& Academic Institutions 